\title{
Tapered uncemented HA-coated femoral stems: a radiological study
}

\author{
A Bakkai, ${ }^{1}$ P Ryan, ${ }^{2}$ IE Goga ${ }^{3}$ \\ MBChB, HDip Orth(SA), FC Orth(SA), Orthopaedic Surgeon, University of KwaZulu-Natal \\ MBChB(UCT), HDip(Orth), MMed(Orth), FC Orth(SA), Consultant Orthopaedic Surgeon \\ 3 MD, FRCS(Edin), FCS Orth(SA), Professor and Head of Department: Orthopaedic Surgery, Inkosi Albert Luthuli Central Hospital, \\ Durban, KwaZulu-Natal, South Africa
}

Corresponding author: Prof IE Goga, PO Box 65167, Reservoir Hills, Durban, 4090, South Africa, Tel: 031240 2160, Email: goga@icon.co.za

\begin{abstract}
Introduction: Numerous national joint registries demonstrate a trend towards the use of uncemented femoral components in total hip arthroplasty. While the results of first-generation uncemented, and some of the second-generation uncemented implants have been unacceptably poor, others, including the fully hydroxyapatite (HA) coated femoral stems, have been excellent with survival rates of greater than $95 \%$ at 20 years. Component longevity is largely related to robust stem fixation to native bone. Adequate stem fixation to the native bone can be determined by clinical assessment and radiological signs of osteointegration. The absence of these radiological signs might be an indication of early loosening. With this in mind, we performed a radiological analysis of the osteointegration of uncemented fully HA-coated femoral stems inserted at our arthroplasty unit.
\end{abstract}

Materials and methods: We performed a retrospective chart and radiological review of patients who had undergone total hip replacement with an uncemented fully HA-coated femoral component over a five-year period. Between March 2003 and March 2008 , 80 patients met the criteria used, and radiological changes around the femoral stem were analysed. The mean patient age at the time of surgery was 59 years, and the most common presenting pathology was avascular necrosis (43\%). The immediate post-operative, six-week, six-month, one-year and five-year radiographs were evaluated.

Results: There were no revisions for stem-related complications. The earliest radiological signs of osteointegration, which included remodelling and trabecular bone formation, were noticed as early as six weeks post-operatively in $4 \%$. At six months and one year, these had increased to $63 \%$ and $100 \%$ respectively. Thereafter, the radiographs demonstrated minimal change and maintained so-called 'radiological silence'.

Conclusion: Osteointegration of fully HA-coated stems occurs in a predictable manner, and is noted in radiographs as early as the six-week follow-up period. Signs of osteointegration can be used as reliable indicators of solid femoral stem fixation after total hip replacement.

Key words: total hip replacement, hydroxyapatite, Corail, osteointegration

Citation: Bakkai A, Ryan P, Goga IE. Tapered uncemented HA-coated femoral stems: A radiological study. SAOJ 2017;16(3):27-30.

DOI 10.17159/2309-8309/2017/v16n3a2

Editor: Prof Anton Schepers, University of the Witwatersrand

Received: December 2014 Accepted: October 2016 Published: August 2017

Copyright: (c) 2017 Bakkai A et al. This is an open-access article distributed under the terms of the Creative Commons Attribution Licence, which permits unrestricted use, distribution and reproduction in any medium, provided the original author and source are credited.

Funding: No benefit of any form has been received from any commercial party related directly or indirectly to the subject of this article.

Conflict of interest: The authors have no conflict of interest in the writing of this study.

The content of this paper is the original work of the authors.

\section{Introduction}

Total hip replacement is an effective treatment for hip pathology, proven to eliminate pain and restore function in the affected joint. Advances in design of both cemented and uncemented hip prostheses, and improvements in bearing surfaces, have resulted in implants that are durable, with excellent long-term survival. ${ }^{1-3}$
Numerous national joint registries demonstrate a trend towards the use of uncemented femoral components in total hip arthroplasty. While the results of first-generation uncemented, and some of the second-generation uncemented implants have been unacceptably poor, others, including the tapered fully hydroxyapatite (HA) coated femoral stems, have been excellent, with survival rates exceeding $96.8 \%$ at 20 years. ${ }^{4,5}$ 
The longevity of uncemented stems relies on initial mechanical stability and thereafter on biological fixation or osteointegration. ${ }^{4,6}$ The radiographic appearance of stability and osteointegration seen in uncemented stems has been described by numerous authors. ${ }^{4,6,10}$

More specifically, the radiographic osteointegration of fully HA-coated stems has been extensively described by Chatelet, ${ }^{7}$ who separated the changes seen into three stages: the insertion stage, followed by the osteointegration stage, and then the period of periprosthetic bone remodelling.

The purpose of our study is to describe the radiographic changes seen around tapered titanium, fully HA-coated femoral stems. Recognition of these manifestations should aid in the understanding of the bone remodelling that occurs about well-fixed HA-coated femoral implants.

\section{Material and methods}

We retrospectively reviewed the charts and radiographs of patients who had undergone primary uncemented total hip replacement with a fully HA-coated stem (Corail, DePuy) during a five-year period, and who had a minimum of five years' radiographic follow-up. Notes were canvassed for demographic and surgical data as well as further interventions or revision. Radiographs were then evaluated as set out below.

Between March 2003 and March 2008, 257 patients had undergone total hip replacement with a fully HA-coated stem (Corail, DePuy). Eighty patients, and 112 hips, met the criteria which included: same surgeon, same surgical approach and regular completed radiological follow-up. The mean patient age at the time of surgery was 59 years (range 31 to 88 years). There were 44 females and 36 males. The surgery was performed on the right hip in 26 patients, on the left in 20, and bilaterally in 33 .

The aetiology of the hip disease was avascular necrosis in 34 patients (42\%), osteoarthritis in 31 (38\%), rheumatoid arthritis in nine (11\%), systemic lupus erythematosus in three (4\%), and other diagnoses in three (4\%) (Figure I).

The aetiology of a vascular necrosis was as follows: $29 \%$ due to steroid use, $26 \%$ due to alcohol, $26 \%$ due to smoking, $11 \%$ posttraumatic, and $8 \%$ due to old Perthe's disease. We acknowledge that there was no documentation of HIV status, as it was not tested routinely at that time. However, currently, we encourage all patients to be tested. All patients were operated by the senior author using the same surgical approach (lateral approach - a modification of the Stracathro method using a single osteo-periosteal sleeve). ${ }^{8}$ The surgical technique for stem insertion was as described by the design surgeon especially with regard to cancellous bone preservation. ${ }^{7}$ The femoral prosthesis utilised in all was the collarless, fully HA-coated, press-fit stem (Corail, DePuy International Ltd). The femoral stem sizes ranged from 8 to 13 .

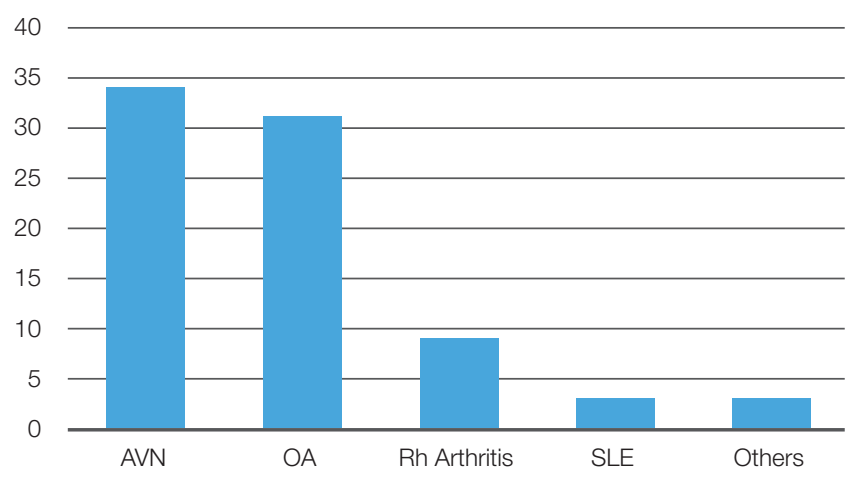

Figure 1. Aetiology of hip disease
The acetabular components were Pinnacle in all patients, head size was 28 and 36 , bearing surface was metal-on-metal in 24; the rest of patients were ceramic and metal-on-polyethylene.

Patients were mobilised on day one or two post-operatively, with weight bearing allowed as tolerated.

The immediate post-operative X-ray was anteroposterior of the pelvis, centred on the pubis, showing the entire prosthesis. The subsequent films included the same anteroposterior view, as well as a lateral view, which included the acetabular component and the most distal aspect of the femoral component.

Radiological changes were reviewed at six weeks, six months, one year, and five years, looking for the following:

- femoral component alignment (valgus, neutral or varus)

- femoral subsidence (defined as an increase in prosthesis-greater trochanter distance $>3 \mathrm{~mm})^{9}$

- analysis of the 14 femoral component zones (as described by Gruen and Johnston) ${ }^{10,11}$ looking for any lucencies, osteolysis, or reactive bony changes (endosteal remodelling, cortical thickening, stress shielding)

\section{Results}

In this series, there were no revisions for stem-related complications. One hip was revised for a large pseudo-tumour, associated with a metal-on-metal bearing surface. At the time of revision, the stem was found to be well fixed and did not require removal. Other complications not related to the femoral stems were: residual sciatic nerve palsy in one patient; iatrogenic fracture of acetabulum treated conservatively and healed during follow-up; periprosthetic fracture; Vancouver type $\mathrm{C}$ managed with open reduction and internal fixation using plate and circulage with retention of the stem.

Radiographic analysis showed the component orientation was neutral in 89, varus in 10, and valgus in 13 patients. There were no cases of subsidence or loosening.

On zonal analysis (Table I), there were no progressive lucencies or osteolytic defects. The earliest bony changes were noted at the six-week follow-up in three hips (4\%). This manifested as an increase in the endosteal density, and bridging of bone trabeculae (Figure 2). The peri-prosthetic osteogenesis, in the area between the prosthesis and the inner cortex, was noted in 50 hips (63\%) at six months, and in all hips (100\%) at one year. Comparison of one-year and five-year follow-up films showed no alteration of the endosteal changes (so-called silent or mute X-rays) (Figures $3 a$ and b).

The endosteal remodelling was most commonly seen in zones 3 and 5 (87\% and 94\% respectively) on the anteroposterior radiograph, and in zone 12 (55\%) on the lateral film (Figures $4 a$ and b).

Table I: Summary of radiographic findings

\begin{tabular}{|l|c|c|c|c|}
\hline Radiology & 6 weeks & $\mathbf{6}$ months & $\mathbf{1}$ year & 5 years \\
\hline Endosteak remodelling & $3(4 \%)$ & $50(63 \%)$ & $80(100 \%)$ & 80 \\
\hline Radiolucent lines & 0 & 0 & 0 & 0 \\
\hline Reactive lines & 0 & 0 & 0 & 3 \\
\hline Pedestal formation & 0 & 0 & 0 & 0 \\
\hline Cortical hypertrophy & 0 & 3 & 3 & 17 \\
\hline Calcar remodelling & 0 & 4 & 4 & 41 \\
\hline Subsidence & 0 & 0 & 0 & 0 \\
\hline Stress shielding & 0 & 0 & 0 & 0 \\
\hline Osteolysis & 0 & 0 & 0 & 1 \\
\hline
\end{tabular}




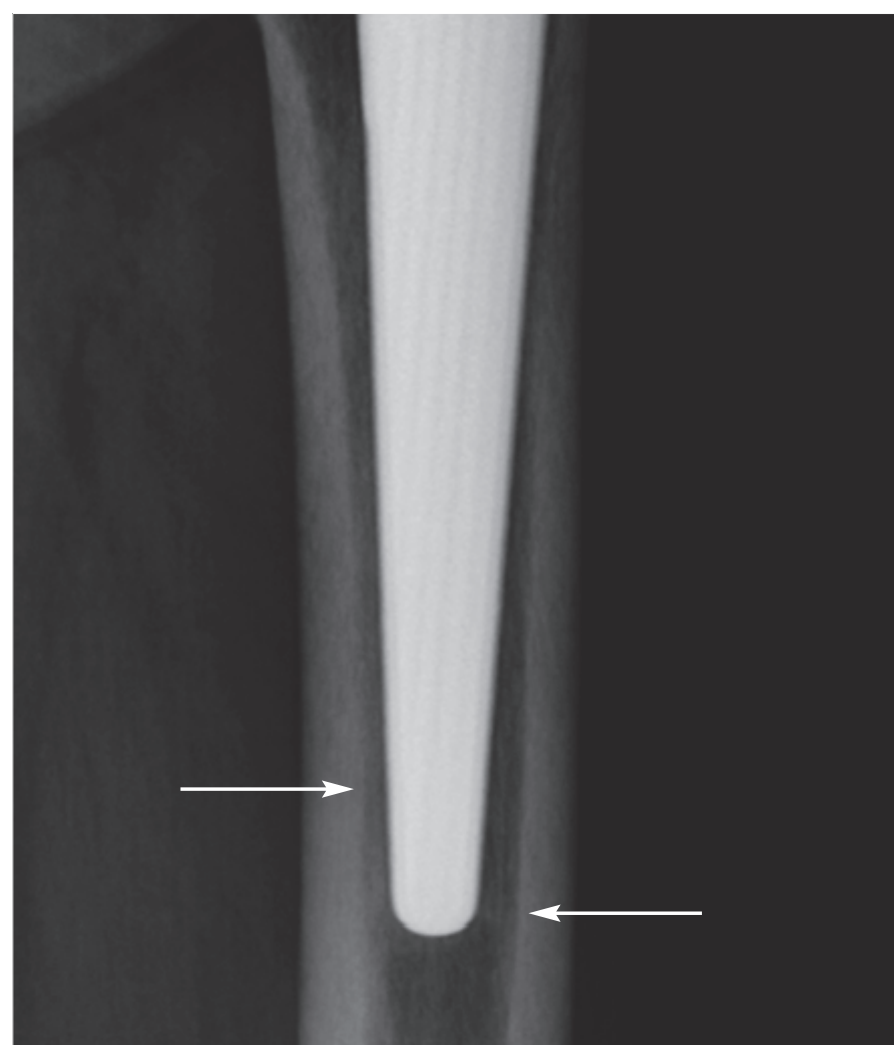

Figure 2. Endosteal changes noted at six weeks post-operatively

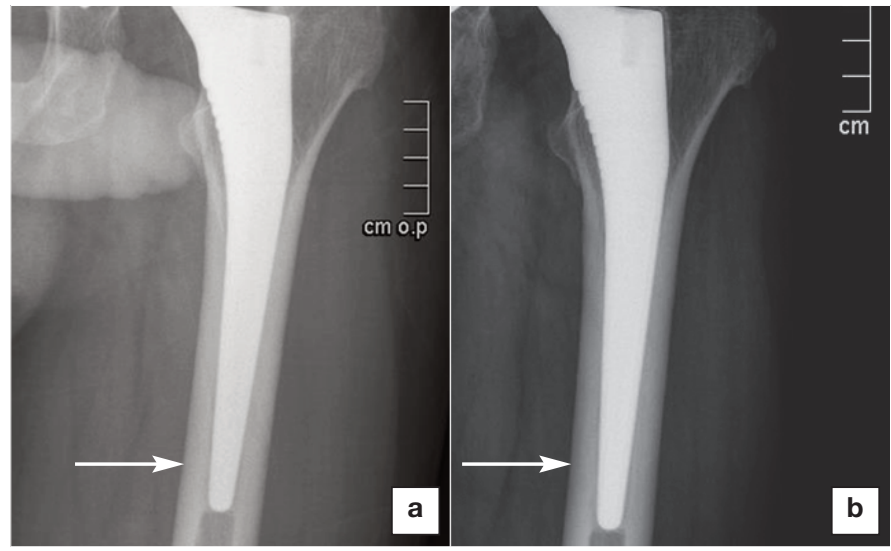

Figure $\mathbf{3} \mathbf{a}$ and $\mathbf{b}$. X-rays at one and five years demonstrating 'radiological silence

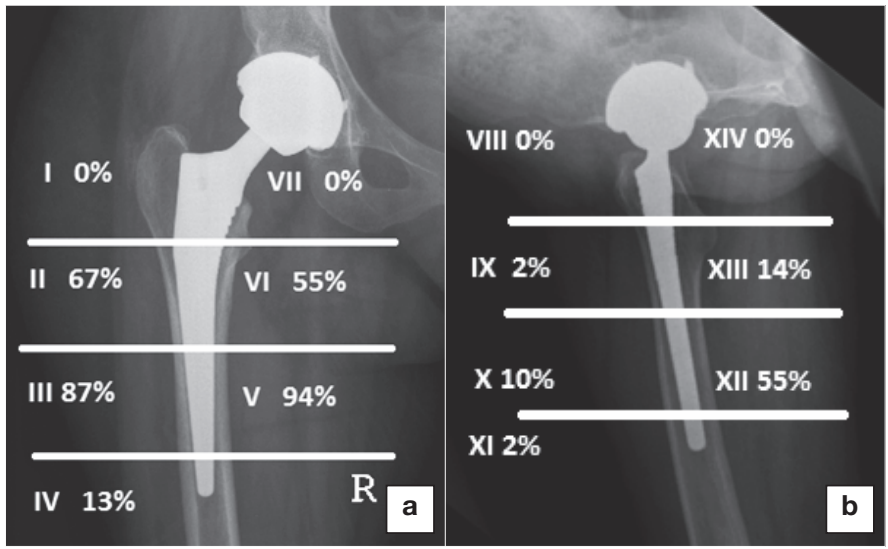

Figure $\mathbf{4 a}$ and $\mathbf{b}$. Distribution of endosteal remodelling noted in AP and lateral views

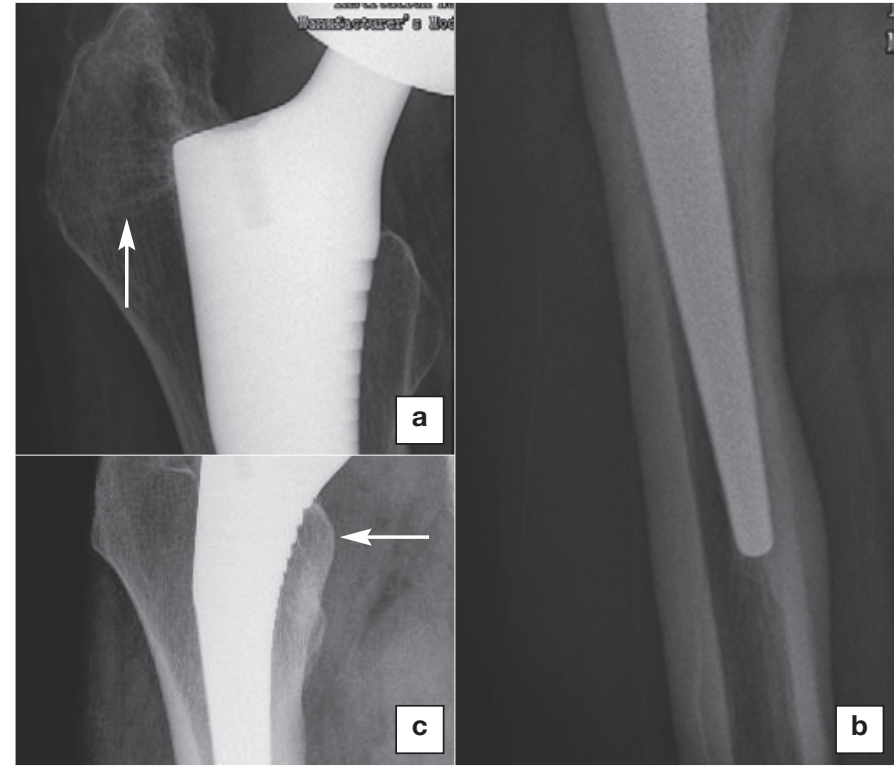

Figure $\mathbf{5 a}, \mathbf{b}$ and $\mathbf{c}$. Radiographs demonstrating parallel bone trabeculae; zone 1 (a), cortical hypertrophy (b), and calcar rounding (c)

Parallel bridging bone trabeculae were seen in zone 1 (Figure 5a), cortical hypertrophy was seen in 17 (Figure 5b), and calcar rounding was seen in 41 (Figure 5c). There was no evidence of proximal stress shielding. Tip on-growth was differentiated from pedestal by the formation of dense oblique trabeculae between the surface of the implant and closest endosteum, while in the pedestal, it was seen as divergent radio-opaque lines separated from the tip of the implant.

\section{Discussion}

Longevity of uncemented components in total hip arthroplasty relies on robust fixation of the implant to the host bone..$^{4,12}$ Osteointegration may be confirmed by the presence of bridging bone formation between the endosteum and the prosthesis. $4,7,9,13$ Long-term remodelling of this peri-prosthetic bone is vital for component survival. ${ }^{4,13}$

The surface finish of the implant plays a vital role in the host bone/component reaction, and different surface finishes have been employed with varying success. ${ }^{13}$ Archibeck et al. reported excellent results with the use of second-generation uncemented implants, with $100 \%$ stem survival at ten years. They attributed this to improved bone ingrowth around porous-coated stems. ${ }^{14}$

The classic description of the radiological signs of uncemented hips described by Engh et al. ${ }^{9}$ relates to the radiological findings in cylindrical medullary locking stems. The distinction between this description and that of the changes seen in $\mathrm{HA}$-coated stems is considered to be extremely important.

HA coatings are known to encourage bone formation around implanted components, and this may be seen as early as three weeks post-operatively on microscopic sections. ${ }^{15}$ This phenomenon is due to the similarity in mineral content of HA to native bone, ${ }^{4,16}$ and this osteointegration results in excellent long-term fixation to host bone, and subsequently to implant survival. ${ }^{4,17}$

\section{Radiological stages}

Jean-Christophe Chatelet $^{7}$ extensively described the radiological stages of osseointegration of fully HA-coated tapered stems, as follows: 


\section{Insertion stage:}

The immediate post-operative X-ray depends on the thickness of cancellous tissue and its compaction strength, the thickness of cortices and the implant size.

\section{Osteointegration stage:}

This includes the first six weeks post surgery in which secondary osteointegration phenomena occur, leading to definitive stem fixation to the host bone.

\section{Remodelling stage:}

This is the stage of bone adaptation to the implant. It begins at six months and includes the phenomenon of endosteal remodelling and other bony changes.

Bone adaptation is an ongoing dynamic process affected by the patient's age, activity levels and bone quality, including osteoporosis.

Endosteal remodelling refers to the bony bridges from the inner cortex towards the stem, which differ according to Gruen zones. It is important to assess not only the presence of these trabecular lines but also the direction of these trabecular lines. As described by Vidalain, 4,7 in zone 1, the trabecular lines run from the greater trochanter towards the stem (tensile forces); in zones 2 to 6 , in the presence of true compressive forces, the lines run oblique toward the stem; and in zone 7 , the calcar remains blunt and rounded.

\section{Other radiological findings}

With regard to other radiological findings, first, the absence of pedestal formation indicates stem fixation distally to cortical bone. Secondly, stress shielding is not usually seen in Corail stems, and this is attributed to the Young's Modulus of Titanium being more similar to bone, and to the mechanical effects of the triple taper design. Thirdly, osteolysis, if it occurs, will be limited to the proximal femur, because of the bone-implant barrier; and lastly, stem malpositioning leads to a hemi-circumferential or hemi-ogival reaction, manifesting as cortical hypertrophy.

In the current study, we note similar radiographic findings. We confirm the positive radiographic signs of endosteal remodelling, calcar rounding, bridging bone trabeculae and cortical hypertrophy, while there were no cases of negative radiological signs (subsidence, stress shielding, osteolysis).

The limitations of our study include the small sample size and the fact that the investigating doctor was not blinded regarding the dates of post-operative $X$-rays assessed. The radiographic signs studied relate to a specific implant (Corail) without comparison to other uncemented fully $\mathrm{HA}$-coated stems.

\section{Conclusion}

This study evaluated the radiographic signs of osteointegration in a consecutive cohort of primary total hip replacements using an uncemented, triple tapered, fully HA- coated femoral stem (Corail, DePuy).

Osteointegration of fully HA-coated stems occurs in a predictable manner, and is noted in radiographs as early as the six-week follow-up period. Signs of osteointegration can be used as reliable indicators of solid femoral stem fixation after total hip replacement. The results of this study are comparable to other reported series using the same prosthesis.

\section{References}

1. Cheung $\mathrm{KW}$, Chiu $\mathrm{KH}$, Chung $\mathrm{KY}$. Long-term result of cementless femoral stem in avascular necrosis of the hip. Hip International: The Journal of Clinical and Experimental Research on Hip Pathology and Therapy. 2014
2. Prins W, Meijer R, Kollen BJ, Verheyen CC, Ettema HB. Excellent results with the cemented Lubinus SP II 130-mm femoral stem at 10 years of follow-up: 932 hips followed for 5-15 years. Acta oOthopaedica. 2014;85(3):276-79.

3. Molloy D, Jack C, Esposito C, Walter WL. A mid-term analysis suggests ceramic on ceramic hip arthroplasty is durable with minimal wear and low risk of squeak. HSS Journal: The Musculoskeletal Journal of Hospital for Special Surgery. 2012;8(3):291-94.

4. Vidalain JP. Twenty-year results of the cementless Corail stem International orthopaedics. 2011;35(2):189-94.

5. Ferrell MS, Browne JA, Attarian DE, Cook C, Bolognesi MP. Cementless porous-coated anatomic total hip arthroplasty at Duke: 18- to 24-year follow-up. Journal of Surgical Orthopaedic Advances. 2009;18(3): 150-54.

6. Epinette JA, Manley MT. Uncemented stems in hip replacement hydroxyapatite or plain porous: does it matter? Based on a prospective study of HA Omnifit stems at 15-years minimum follow-up. Hip International: The Journal of Clinical and Experimental Research on Hip Pathology and Therapy. 2008;18(2):69-74.

7. Chatelet JC. The radiology of the bone/stem interface: a time-tested couple. The Corail Hip System - A practical approach based on 25 years experience. Heidelberg Dordrecht London New York: Springer; 2011. pp.106-107.

8. McLaughlin J. The Stracathro approach to the hip. Journal of Bone and Joint Surgery (Br) 1984;66(1):30-31.

9. Engh CA, Massin P, Suthers KE. Roentgenographic assessment of the biologic fixation of porous-surfaced femoral components. Clinical Orthopaedics and Related Research. 1990(257):107-28.

10. Gruen TA, McNeice GM, Amstutz HC. 'Modes of failure' of cemented stem-type femoral components: a radiographic analysis of loosening. Clinical Orthopaedics and Related Research. 1979(141):17-27.

11. Johnston RC, Fitzgerald RH, Jr, Harris WH, Poss R, Muller ME, Sledge $\mathrm{CB}$. Clinical and radiographic evaluation of total hip replacement. A standard system of terminology for reporting results. Journal of Arthroplasty 2007;22(4 Suppl. 1):71-74

12. Chambers B, St Clair SF, Froimson MI. Hydroxyapatite-coated tapered cementless femoral components in total hip arthroplasty. The Journal of Arthroplasty. 2007;22(4 Suppl 1):71-4.

13. Coathup MJ, Blunn GW, Flynn N, Williams C, Thomas NP. A comparison of bone remodelling around hydroxyapatite-coated, porous-coated and grit-blasted hip replacements retrieved at post-mortem. The Journal of Bone and Joint Surgery (Brit). 2001;83(1):118-23.

14. Archibeck MJ, Berger RA, Jacobs JJ, Quigley LR, Gitelis S, Rosenberg $A G$, et al. Second-generation cementless total hip arthroplasty. Eight to eleven-year results. The Journal of Bone and Joint Surgery (Am). 2001;83-A(11):1666-73.

15. Kusakabe H, Sakamaki T, Nihei K, Oyama Y, Yanagimoto S, Ichimiya $\mathrm{M}$, et al. Osseointegration of a hydroxyapatite-coated multilayered mesh stem. Biomaterials. 2004;25(15):2957-69.

16. Ergun C, Liu H, Webster TJ, Olcay E, Yilmaz S, Sahin FC. Increased osteoblast adhesion on nanoparticulate calcium phosphates with higher $\mathrm{Ca} / \mathrm{P}$ ratios. Journal of Biomedical Materials Research Part A. 2008;85(1):236-41.

17. Tanzer M, Kantor S, Rosenthall L, Bobyn JD. Femoral remodeling after porous-coated total hip arthroplasty with and without hydroxyapatitetricalcium phosphate coating: a prospective randomized trial. The Journal of Arthroplasty. 2001;16(5):552-58 